\title{
EFFECT OF TWO MUSHROOM VARIETIES INTAKE ON SERUM TRIGLYCERIDES, CHOLESTEROL FRACTIONS AND SERUM GLUCOSE LEVELS IN ALBINO RATS
}

\author{
By \\ M. Kamal E. Youssef", Farouk, M. El-Tellawy" \\ Amany Osama ${ }^{* * *}$ and Hend, M. A. Mohamed ${ }^{* * * *}$ \\ * Food Science \& Technology Department, Faculty of Agriculture, Assiut \\ University \\ ** Food Science \& Technology Department, Home Economics Department, Ain \\ Shams University \\ *** Lecturer of Biochemistry Department, Faculty of Medicine, Assiut \\ University \\ **** Home Economics Department, Faculty of Specific Education, Assiut \\ University
}

مجلة بحوث التربية النوعية - جامعة المنصورة

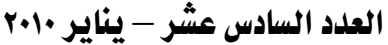




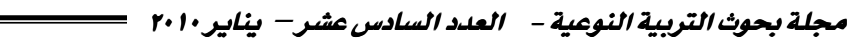

EFFECT OF TWO MUSHROOM VARIETIES INTAKE ON SERUM TRIGLYCERIDES, CHOLESTEROL FRACTIONS AND SERUM GLUCOSE LEVELS IN ALBINO RATS

\author{
$B y$ \\ M. Kamal E. Youssef", Farouk, M. El-Tellawy**
Amany Osama ${ }^{* * * *}$ and Hend, M. A. Mohamed
}

\title{
Abstract
}

The present investigation was carried out in an attempt to assess the effect of nutrition with the two studied mushroom varieties namely, (Agaricus bisporus) and (Pleurotus ostreatus) on triglycerides and cholesterol fractions levels in albino rats, namely: total cholesterol, HDLcholesterol, LDL-cholesterol and glucose content in the blood serum of the experimental albino rats after feeding with the four studied mushroom varieties such 10\% (Agaricus bisporus), 10\% (Pleurotus ostreatus), 5\% (Agaricus bisporus)and 5\% (Pleurotus ostreatus).

The experiment included (56) males white albino rats (Sprague dawley strain) weighing between $(100-120 \mathrm{~g})$ divided into 6 groups with every group included 6 rats. Rats were housed individually in wire cages under the normal laboratory conditions and fed on the basal diet for a week as adaptation period. Daily administrations were continued for two successive periods (6) weeks each. In the first period one group was used as control and was fed on basal diet, including casein $(12.5 \%)$, corn oil $(10 \%)$, vitamin mixture $(1 \%)$, salt mixture $(3.5 \%)$, cellulose $(5 \%)$, choline chloride $(0.2 \%)$ and corn starch $(67.8 \%)$. While, the other five groups were fed hyperlipidemic diet including (basal diet supplemented by $10 \%$ animal fat excluding $10 \%$ corn plus $1 \%$ cholesterol). In the second period, one group of hyperlipidiemic rats was fed on hyperlipidemic diet supplemented with different levels of the two studied mushroom varieties (Agaricus bisporus) and (Pleurotus ostreatus).

Blood samples were collected from the retro-orbital sinus under rat eye in a clean sterile centrifuge tube by the end of the experiment.

\footnotetext{
* Food Science \& Technology Department, Faculty of Agriculture, Assiut University

** Food Science \& Technology Department, Home Economics Department, Ain Shams University

*** Lecturer of Biochemistry Department, Faculty of Medicine, Assiut University

**** Home Economics Department, Faculty of Specific Education, Assiut University
} 
Samples were tightly kept in a sealed aliquot tube at $-20^{\circ} \mathrm{C}$ until biochemical assays.

There were significant differences between untreated group and all other (5) studied groups of the experimental rats $(\mathrm{P}<0.05)$ in the serum triglycerides, total cholesterol, HDL cholesterol, LDL cholesterol, VLDL cholesterol and serum glucose levels, while group (3) (treated group fed on hyperlipidemic diet plus $10 \%$ Agaricus bisporus) recorded the lowest mean.

Key Words:

Mushrooms (Agaricus bisporus), (Pleurotus ostreatus), triglycerides, cholesterol, hyperlipidemic and glucose. 


\section{Introduction}

In nature many thousands of species of mushrooms are located varying in form, color, size, strength and appearance and the nature of growth, taste with very tasty flavor. Most of such types have delicious flavor, however a few percentage of them are toxic kinds such as Agaricus compestris, Pleurotus ostreatus, Lentinus Edodes, Flammulina Velutipes, Ganoderma Lucidium and Agaricus Blazei. (Hussain et al. 2006).

Edible mushrooms had been widely utilized as a human foods for centuries and had been appreciated for texture and flavor as well as some medicinal and tonic attributes (Manzi et al., 2001). However, the awarness of mushrooms as a healthy food and as an important source of biological active substances with medicinal value had only recently emerged (Cheung, 1999). Mushrooms are considered as healthy food because they are low in calories and fat but rich in proteins and dietary fibers (Manzi et al., 1999).

Kuruswa et al. (1982) reported that Mushroom effectively lowered plasma cholesterol in laboratory animals. Shahdat et al., 2003 reported that the feeding of $5 \%$ powder of the fruiting bodies of $P$. ostreatus mushrooms to hypercholesterolaemic rats reduced their plasma total cholesterol by approximately $28 \%$, low density lipoprotein-cholesterol by approximately $55 \%$, triglyceride by approximately $34 \%$, non-esterified fatty acid by approximately $30 \%$ and total liver cholesterol levels by $>34 \%$, with a concurrent increase in plasma high-density lipoprotein cholesterol concentration of $>21 \%$. However, these effects were not observed in mushroom-fed normocholesterolaemic rats. Mushroom feeding significantly increased plasma fatty acid unsaturation in both normo- and hypercholesterolaemic rats and the 5\% (Pleurotus ostreatus) supplementation provides health benefits, at least partially, by acting on the atherogenic lipid profile in the hypercholesterolaemic condition.

Fukushima et al., (2000) reported that (Agaricus bisporous) decreases serum low-density lipoprotein-cholesterol (LDL-C) by increasing the expression of low-density lipoprotein (LDL) receptor mRNA levels and LDL receptor activity.

Hashimoto et al., (1999) and Hashimoto et al., (2001) suggested that one of the most important food components that helped reduce serum cholesterol was its polyunsaturated fatty acid content. 
Stamlo et al., (1986) mentioned that mushroom was lowering of high serum cholesterol levels and played a significant role in the prevention of atherosclerosis.

Higher fungi are an ideal dietary substance for the prevention and treatment of hypercholesterolemia due to the high content of dietary fiber, protein and microelements and the presence of plant sterols, as well as the low energy content. Lowering of circulating cholesterol especially the low density lipoprotein (LDLC) fraction can prevent arrest even reverse coronary atherosclerosis (Barter and Rye 1996).

Grundy (1986) reported that High-density lipoprotein (HDL) had been called the "good" cholesterol because high levels of it reduce an individual's tendency to develop atherosclerosis. HDL protects the blood vessels by removing some of the cholesterol from the arterial walls and possibly by slowing cholesterol's entry into tissues (Mahley et al. 1978). HDL also promotes the production of prostacydin, a substance that inhibits clotting along the inner walls of arteries (Byrne 1991).

Anon (2003a) reported that diabetic patients who included 50 grams of fiber in their daily diet lowered their glucose levels by $10 \%$. The hightfiber diet also decreased insulin levels in the blood and lowered blood lipid concentrations in patients with type II diabetes, or non insulin dependent diabetes mellitus, the most prevalent type of diabetes.

Schaeffiner et al. (2003) stated that when the body had too much of LDL above $160 \mathrm{mg} / \mathrm{dl}$, the LDL or "bad cholesterol" starts to accumulate along the interior walls of arteries (blood vessels supplying oxygen to the heart and brain), causing a build up or forming a plaque and even then, blood clots could also appear on the plaque restricting oxygen, blood and nutrients from getting to the heart and brain. Such a phenomenon could inevitability cause heart disease leading to heart attack or stroke.

Oyetayo (2006), reported that total body weight gain of rats fed mushroom diets were not significantly different $(\mathrm{P}>0.05)$ after 28 day feeding trial, plasma total cholesterol, low density lipoprotein cholesterol and triglycerides concentrations were found to be significantly lower $(\mathrm{P}<$ 0.05) than control while high density lipoprotein cholesterol were significantly higher $(\mathrm{P}<0.05)$ and edible mushrooms have hypocholestolemic effects and could serve an important purpose in the prevention of atherosclerosis. 
Bobek et al., (1993) found that in series of experiments that long term dietary supplementation with $5 \%$ dried oyster mushroom fruiting bodies can effectively suppress dietary induced hypercholesterolemia in rats.

Pavel et al., (1997) reported that that diet supplemented with 1\% oyster mushroom did not significantly affect the level of serum cholesterol or triacylglycerols and the diets supplemented with $5 \%$ oyster mushroom significantly reduced cholesterol levels, LDL, VLDL in serum in the experimental rats, while HDL was significantly higher in the serum.

El-Gengaihi et al. (2004) reported that vegetable oils markedly reduce blood cholesterol levels when substituted for animal fat in diets.

This investigation was carried out in an attempt to study the effect of the two studied mushrooms varieties on blood lipid profile (total cholesterol, HDL cholesterol, LDL cholesterol, VLDL cholesterol and triglycerides) in the experimental albino rats.

\section{Material and Method \\ Materials: \\ Source of Samples:}

$40 \mathrm{~kg}$ of the two mushrooms varieties namely: (Pleurotus ostreatus) and (Agaricus bisporus) were procured from Food Technology Institute (Agriculture Research Center) and Metro local market Giza, Cairo; respectively in March 2008.

\section{Preparation of Samples:}

The mycelia were cleaned with a minimal amount of distilled water to remove the dust and solids. The rind (outer covering) of the mycelia were removed to avoid any contamination that might come from the compost and the plastic wrapping during cultivation.

Two mushroom varieties were dried in a drying oven at $55-60^{\circ} \mathrm{C}$ for $6-8$ hours to complete drying, thereafter were milled and kept in polyethylene bags at $5^{\circ} \mathrm{C}$ until required for analysis (Moharram et al., 2008).

\section{Experimental Animals:}

Fifty six adult male white albino rats (Sprague dawley strain) weighing between (100 and $120 \mathrm{~g}$ ) provided from the animal house of the 
Faculty of Medicine, Assiut University were housed individually in wire cages under the normal laboratory conditions and fed on the basal diet for a week as adaptation period.

\section{Basal diet and untreated hyperlipidemic diet:}

The basal diet used is outlined in Table (1), (2) and (3)

Table (1): Constituents of the basal diet for 100 gm diet $^{*}$.

\begin{tabular}{|l|c||}
\hline \multicolumn{1}{|c|}{ Item } & \% \\
\hline \hline Corn starch & 67.8 \\
\hline Casein & 12.5 \\
\hline Corn oil & 10.0 \\
\hline Vitamins mixture & 1.0 \\
\hline Salt mixture & 3.5 \\
\hline Cellulose & 5.0 \\
\hline Choline chloride & 0.2 \\
\hline Total & $100.0 \%$ \\
\hline
\end{tabular}

*(El-Sayed, 2001) and (Ilwy, 2003).

Table (2): Constituents of vitamins mixture used in the basal diet*

\begin{tabular}{|c|c|}
\hline \multicolumn{2}{|l|}{ Vitamins Mixture } \\
\hline Item & Amount (gm) \\
\hline Vitamin A plamitate $500.000 \mathrm{IU} / \mathrm{gm}$ & 0.80 \\
\hline Vitamin $\mathrm{D}_{3} 100.000 \mathrm{IU} / \mathrm{gm}$ & 1.00 \\
\hline Vitamin E acetate $500 \mathrm{IU} / \mathrm{gm}$ & 10.00 \\
\hline Menadione sodium bisulfite $62.5 \%$ mendadione & 0.08 \\
\hline Biotin $1.0 \%$ & 2.00 \\
\hline Cyano cobalaming $0.01 \%$ & 1.00 \\
\hline Folic acid & 0.20 \\
\hline Nicotinic acid & 3.00 \\
\hline Calcium pantothenate & 1.60 \\
\hline Pyridoxine-Hcl & 0.70 \\
\hline Riboflavin & 0.60 \\
\hline Thiamin-Hcl & 0.60 \\
\hline Sucrose & 978.42 \\
\hline Total & 1000.00 \\
\hline
\end{tabular}

Anon (1977). 
Table (3): Constituents of the salt mixture used in the basal diet":

\begin{tabular}{|c|c|}
\hline \multicolumn{2}{|l|}{ Salt Mixture } \\
\hline Item & Amount (gm) \\
\hline Calcium phosphate, diabase $29.5 \% \mathrm{Ca}, 22.8 \% \mathrm{P}$ & 500.00 \\
\hline Magnesium oxide $60.3 \%$ ug & 24.00 \\
\hline Potassium citrate, $1 \mathrm{H}_{2} \mathrm{O}, 36.2 \% \mathrm{~K}$ & 220.00 \\
\hline Postassium sulfate $44.9 \% \mathrm{~K}, 18.4 \% \mathrm{~S}$ & 52.00 \\
\hline Sodium chloride $39.3 \% \mathrm{Na}, 60.7 \% \mathrm{Cl}$ & 74.00 \\
\hline Chromium potassium sulfate $12.0 \mathrm{H}_{2} \mathrm{O}, 10.4 \% \mathrm{Cr}$ & 0.55 \\
\hline Cupric carbonate $57.5 \% \mathrm{Cu}$ & 0.30 \\
\hline Potassium iodate $59.3 \% \mathrm{I}$ & 0.01 \\
\hline Ferric citrate $21.2 \% \mathrm{Fe}$ & 6.00 \\
\hline Manganous carbonate $47.8 \% \mathrm{Mn}$ & 3.50 \\
\hline Sodium selenite $45.7 \% \mathrm{Se}$ & 0.01 \\
\hline Zinc carbonate $52.1 \mathrm{Zn}$ & 1.60 \\
\hline Sucrose & 118.03 \\
\hline Total & 1000.00 \\
\hline
\end{tabular}

Anon (1980).

The untreated hyperlipidemic diet used is outlined in tables (2), (3) and (4).

Table (4): Constituents of the hyperlipidemic diet for $100 \mathrm{gm} \mathrm{diet}$.

\begin{tabular}{||l|c||}
\hline \multicolumn{1}{|c|}{ Item } & \% \\
\hline \hline Corn starch & 66.80 \\
\hline Casein & 12.5 \\
\hline Animal fat & 10.00 \\
\hline Cholesterol & 1.00 \\
\hline Vitamins mixture & 1.00 \\
\hline Salt mixture & 3.50 \\
\hline Cellulose & 5.00 \\
\hline Choline chloride & 0.2 \\
\hline Total & $100.0 \%$ \\
\hline \hline
\end{tabular}

*(El-Sayed 2001) and (Ilwy, 2003) 


\section{Design of the experiment:}

The rats were randomly allocated into (6) main groups of (6) rats each. Daily administrations were continued for two successive periods (6) weeks each. In the first period one group was used as control and was fed on basal diets, while the other five groups were fed the hyperlipidemic diet as concluded by Abd-El-Maksoud et al. (1996). In general rats were classified as following:

Group 1: Control group fed on basal diet.

Group 2: Untreated group fed on hyperlipidemic diet.

Group 3: Treated group fed on hyperlipidemic diet plus $10 \%$ dried mushroom (Agaricus bisporus).

Group 4: Treated group fed on hyperlipidemic diet plus $10 \%$ dried mushroom (Pleurotus ostreatus).

Group 5: Treated group fed on hyperlipidemic diet plus 5\% dried mushroom (Agaricus bisporus).

Group 6: Treated group fed on hyperlipidemic diet plus 5\% dried mushroom (Pleurotus ostreatus).

\section{Blood sampling:}

At the end of each experiment, rats were fasted overnight and anesthetized.

Blood samples were collected from the retro-orbital plexus from all animals of each group into clean, dry and labeled tube. The tubes contained heparin (10.0 IU / ml) as anticoagulant. Blood was centrifuged (3500 r-p. m for $15 \mathrm{~min}$ ) to separate plasma which was tightly kept in sealed aliquot tubes at $-20^{\circ} \mathrm{C}$ until biochemical assays according to Ilwy (2003).

\section{Methods}

\section{Biochemical methods:}

Prepared samples (as mentioned in 2.1.6) were used to study the following biochemical parameters using PHOTO Mech 301-D+ spectrophotometer (Optima).

\section{Determination of serum triglycerides:}

Fully enzymatic determination of total triglycerides in serum was 


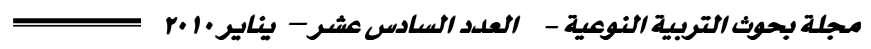

estimated spectrophtometrically at $500 \eta \mathrm{m}$ according to the method of Wahlefeld (1974).

Determination of serum total cholesterol:

Enzymatic determination of cholesterol was carried out according to the method of Allian et al. (1974) using kits purchased from Stanbio (Texas, USA).

\section{Determination of High Density Lipoprotein (HDL) cholesterol:}

The kits were provided from Stanbio, Lab., Inc. Texas. According to Warnick et al. (1983).

\section{Low Density Lipoprotein (LDL) cholesterol calculation:}

LDL was calculated by the difference between total cholesterol, HDL cholesterol and triglyceride, according to Friedewald $\boldsymbol{e t}$ al. (1972).

\section{Determination of serum glucose:}

Serum glucose level was analyzed by calorimetric procedures kits developed by Diamond diagnostics kits Cairo, Egypt using $550 \eta \mathrm{m}$. according to Trinder (1969).

\section{Statistical analysis:}

Data was analyzed with applying of variance (ANOVA) procedures by using the MSTAT-C Statistical software package (Russell 1983). Where the F-test showed significant differences among means Duncan (1955) performed at the 0.05 level of probability to separate means.

\section{Results and discussion}

\section{Serum triglycerides in the two studied mushroom varieties:}

The results given in table (5) revealed that the blood serum triglycerides of the experimental animals showed significant differences among all the six studied groups at $(\mathrm{P}<0.05)$.

However, the data regarding the blood serum triglycerides were $(243.1 \pm 3.89 \mathrm{mg} / \mathrm{dl}$ ) for group (2) of experimental rats (untreated group fed on hyperlipidemic diet).

Likewise, the blood serum triglycerides decreased significantly at $(\mathrm{P}$ $<0.05)$ recording $(177.2 \pm 4.61 \mathrm{mg} / \mathrm{dl})$ for group (3) of rat (treated group fed on hyperlipidemic diet plus 10\% Agaricus bispours / rat), (194.1 \pm 3.74 
$\mathrm{mg} / \mathrm{dl}$ ) for group (4) of rat (treated group fed on hyperlipidemic deit plus $10 \%$ Pleurotus ostreatus / rat), $(211.1 \pm 3.06 \mathrm{mg} / \mathrm{dl})$ for group (5) of rat (treated group fed on hyperlipidemic diet plus 5\% Agaricus busporus / rat) and $(228.0 \pm 3.05 \mathrm{mg} / \mathrm{dl})$ for group (6) of rat (treated group fed on hperlipidemic diet plus 5\% Pleurotus ostreatus / rat); respectively.

The data given in table (5) revealed that the mean values among all six studied treatments recorded significant decrease starting from 193.0 and reaching 183.2 by the end of the feeding experiment.

The present data given in table (5) on blood serum triglycerides in the serum of the experimental animals was agreed with Oyetayo (2006) who found that, rats fed mushroom diets were significantly lower triglycerides concentrations $(\mathrm{P}<0.05)$.

Table (5): Effect of the six studied groups on the serum triglycerides content (mg / dl) of the experimental rats.

\begin{tabular}{|c|c|c|c|c|c|c|c|}
\hline \multirow[t]{2}{*}{$\begin{array}{c}\text { Time of } \\
\text { observation }\end{array}$} & 它 & 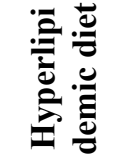 & 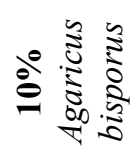 & 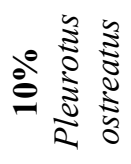 & 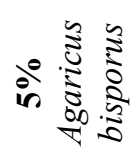 & 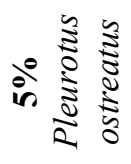 & \multirow[t]{2}{*}{ Mean } \\
\hline & Group 1 & Group 2 & Group 3 & Group 4 & Group 5 & Group 6 & \\
\hline $\begin{array}{c}\text { End of } 1^{\text {st }} \text { week } \\
\pm \text { S. E. }\end{array}$ & $\begin{array}{l}132.1^{\mathrm{s}} \\
\pm 4.02 \\
\end{array}$ & $\begin{array}{l}208.6^{\text {hij }} \\
\pm 0.81 \\
\end{array}$ & $\begin{array}{l}190.4^{\operatorname{lm}} \\
\pm 3.41 \\
\end{array}$ & $\begin{array}{l}199.1^{\mathrm{jk}} \\
\pm 2.51 \\
\end{array}$ & $\begin{array}{l}207.8^{\mathrm{ij}} \\
\pm 2.66 \\
\end{array}$ & $\begin{array}{l}220.0^{\mathrm{fg}} \\
\pm 2.21\end{array}$ & $\begin{array}{l}193.0^{\mathrm{D}} \\
\pm 5.43 \\
\end{array}$ \\
\hline $\begin{array}{c}\text { End of } 2^{\text {nd }} \text { week } \\
\pm \text { S. E. }\end{array}$ & $\begin{array}{l}137.2^{\mathrm{rs}} \\
\pm 3.93 \\
\end{array}$ & $\begin{array}{l}227.4^{\mathrm{ef}} \\
\pm 1.31 \\
\end{array}$ & $\begin{array}{l}200.0^{\mathrm{jk}} \\
\pm 2.90 \\
\end{array}$ & $\begin{array}{l}214.8^{\text {ghi }} \\
\pm 1.87 \\
\end{array}$ & $\begin{array}{l}229.6^{\mathrm{e}} \\
\pm 1.15 \\
\end{array}$ & $\begin{array}{l}242.9^{\mathrm{cd}} \\
\pm 3.18 \\
\end{array}$ & $\begin{array}{l}208.6^{\mathrm{B}} \\
\pm 6.50 \\
\end{array}$ \\
\hline $\begin{array}{c}\text { End of } 3^{\text {rd }} \text { week } \\
\pm \text { S. E. }\end{array}$ & $\begin{array}{l}141.3^{\mathrm{qrs}} \\
\pm 6.14\end{array}$ & $\begin{array}{l}250.0^{\mathrm{c}} \\
\pm 2.66\end{array}$ & $\begin{array}{l}203.2^{j} \\
\pm 2.82\end{array}$ & $\begin{array}{l}217.7^{\text {gh }} \\
\pm 1.75\end{array}$ & $\begin{array}{l}232.2^{\mathrm{e}} \\
\pm 1.77\end{array}$ & $\begin{array}{l}247.0^{c} \\
\pm 2.10\end{array}$ & $\begin{array}{l}215.2^{\mathrm{A}} \\
\pm 6.94\end{array}$ \\
\hline $\begin{array}{c}\text { End of } 4^{\text {th }} \text { week } \\
\pm \text { S. E. }\end{array}$ & $\begin{array}{l}144.0^{\mathrm{qr}} \\
\pm 4.86 \\
\end{array}$ & $\begin{array}{l}258.8^{b} \\
\pm 2.90 \\
\end{array}$ & $\begin{array}{l}175.8^{\mathrm{n}} \\
\pm 5.06 \\
\end{array}$ & $\begin{array}{l}192.4^{\mathrm{klm}} \\
\pm 3.64\end{array}$ & $\begin{array}{l}209.0^{\mathrm{hij}} \\
\pm 2.72\end{array}$ & $\begin{array}{l}235.8^{\mathrm{de}} \\
\pm 1.69 \\
\end{array}$ & $\begin{array}{l}202.6^{\mathrm{C}} \\
\pm 7.15 \\
\end{array}$ \\
\hline $\begin{array}{c}\text { End of } 5^{\text {th }} \text { week } \\
\pm \text { S. E. }\end{array}$ & $\begin{array}{l}148.2^{\mathrm{pq}} \\
\pm 5.30\end{array}$ & $\begin{array}{l}267.6^{\mathrm{a}} \\
\pm 1.37\end{array}$ & $\begin{array}{l}155.4^{\mathrm{op}} \\
\pm 4.60\end{array}$ & $\begin{array}{r}177.7^{\mathrm{n}} \\
\pm \quad 3.54\end{array}$ & $\begin{array}{l}200.0^{\mathrm{jk}} \\
\pm 2.66\end{array}$ & $\begin{array}{l}218.8^{\mathrm{fg}} \\
\pm 2.67\end{array}$ & $\begin{array}{l}194.6^{\mathrm{D}} \\
\pm 7.67\end{array}$ \\
\hline $\begin{array}{c}\text { End of } 6^{\text {th }} \text { week } \\
\pm \text { S. E. }\end{array}$ & $\begin{array}{l}160.8^{\circ} \\
\pm 4.02 \\
\end{array}$ & $\begin{array}{l}246.1^{\mathrm{c}} \\
\pm 7.29 \\
\end{array}$ & $\begin{array}{l}138.2^{\mathrm{rs}} \\
\pm 2.97 \\
\end{array}$ & $\begin{array}{l}163.0^{\circ} \\
\pm 2.64 \\
\end{array}$ & $\begin{array}{l}187.8^{\mathrm{m}} \\
\pm 3.73 \\
\end{array}$ & $\begin{array}{r}203.4^{j} \\
\pm 5.04 \\
\end{array}$ & $\begin{array}{l}183.2^{\mathrm{E}} \\
\pm 6.70 \\
\end{array}$ \\
\hline Mean & $\begin{array}{l}143.9^{\mathrm{E}} \\
\pm 2.45\end{array}$ & $\begin{array}{l}243.1^{\mathrm{A}} \\
\pm 3.89\end{array}$ & $\begin{array}{l}177.2^{\mathrm{E}} \\
\pm 4.61\end{array}$ & $\begin{array}{l}194.1^{\mathrm{D}} \\
\pm 3.74\end{array}$ & $\begin{array}{l}211.1^{\mathrm{C}} \\
\pm 3.06\end{array}$ & $\begin{array}{l}228.0^{\mathrm{B}} \\
\pm 3.05\end{array}$ & \\
\hline
\end{tabular}

S. E. = Standard Error

Values followed by the same letter within the same column were not significantly different $(\mathrm{P}<0.05)$.
F. Test (A) (week) $=86.96^{* *}$
F. Test (B) (Tre.) $=836.67^{* *}$
F. Test $(\mathrm{AB})=31.47^{* *}$ 


\section{Serum total cholesterol in the two studied mushroom varieties:}

The results given in table (6) revealed that the serum total cholesterol values significant differences among all the six studied groups at $(\mathrm{P}<0.05)$ in experimental period.

However, the data regarding the blood serum total cholesterol were (283.7 $\pm 9.38 \mathrm{mg} / \mathrm{dl}$ ) for group (2) of experimental rats (untreated group fed on hyperlipidemic diet).

Meanwhile, the blood serum total cholesterol in groups $(3,4,5$ and 6) decreased significantly at $(\mathrm{P}<0.05)$ recording $(193.5 \pm 3.02 \mathrm{mg} / \mathrm{dl}$, $204.5 \pm 2.99 \mathrm{mg} / \mathrm{dl}, 221.7 \pm 3.00 \mathrm{mg} / \mathrm{dl}$ and $228.4 \pm 3.19 \mathrm{mg} / \mathrm{dl}$ ); respectively for these four groups of rats (treated group fed on hyperlipidemic diet plus 10\% Agaricus bisporus, treated group fed on hyperlimpidemic diet plus $10 \%$ Pleurotus ostrreats, treated group fed on hyperlipidemic diet plus 5\% Agaricus bisporus and treated group fed on hyperlipidemic diet plus 5\% Pleurotus ostrreats / rats); respectively.

The data given in table (6) revealed that the mean values among all six studied treatments recorded significant decrease starting from 201.2 and reaching 202.8 by the end of the feeding experiment.

The present results given in table (6) were agreed with Stamlo et al., (1986) who found mushroom was lowering of high serum cholesterol levels and played a significant role in the prevention of atherosclerosis. 
Table (6): Effect of the six studied groups on the serum cholesterol content (mg / dl) of the experimental rats.

\begin{tabular}{|c|c|c|c|c|c|c|c|}
\hline \multirow[t]{2}{*}{$\begin{array}{c}\text { Time of } \\
\text { observation }\end{array}$} & $\stackrel{\bar{\Xi}}{0}$ & لِّ & 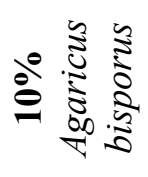 & 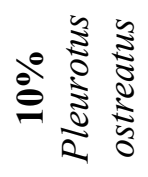 & 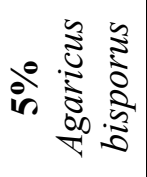 & 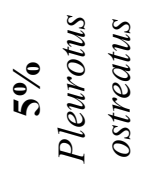 & \multirow[t]{2}{*}{ Mean } \\
\hline & Group 1 & Group 2 & Group 3 & Group 4 & Group 5 & Group 6 & \\
\hline $\begin{array}{c}\text { End of } 1^{\text {st }} \text { week } \\
\pm \text { S. E. }\end{array}$ & $\begin{array}{c}95.4^{\mathrm{s}} \\
\pm 2.64\end{array}$ & $\begin{array}{l}223.2^{\text {hi }} \\
\pm 0.82\end{array}$ & $\begin{array}{l}207.9^{\mathrm{k}} \\
\pm 2.54\end{array}$ & $\begin{array}{l}217.0^{\mathrm{ij}} \\
\pm 2.55\end{array}$ & $\begin{array}{c}227.6^{\mathrm{fgh}} \\
\pm 2.84\end{array}$ & $\begin{array}{l}236.2^{\mathrm{def}} \\
\pm 6.12\end{array}$ & $\begin{array}{l}201.2^{\mathrm{C}} \\
\pm 9.02\end{array}$ \\
\hline $\begin{array}{c}\text { End of } 2^{\text {nd }} \text { week } \\
\pm \text { S. E. }\end{array}$ & $\begin{array}{l}104.2^{r} \\
\pm 3.06\end{array}$ & $\begin{array}{l}233.0^{\mathrm{efg}} \\
\pm 0.95\end{array}$ & $\begin{array}{l}208.6^{\mathrm{jk}} \\
\pm 2.60\end{array}$ & $\begin{array}{l}219.4^{\mathrm{hi}} \\
\pm 2.52\end{array}$ & $\begin{array}{c}234.6^{\mathrm{efg}} \\
\pm 3.70\end{array}$ & $\begin{array}{l}243.8^{\mathrm{cd}} \\
\pm 2.42\end{array}$ & $\begin{array}{l}207.3^{\mathrm{B}} \\
\pm 8.87\end{array}$ \\
\hline $\begin{array}{c}\text { End of } 3^{\text {rd }} \text { week } \\
\pm \text { S. E. }\end{array}$ & $\begin{array}{l}113.6^{\mathrm{q}} \\
\pm 3.43 \\
\end{array}$ & $\begin{array}{l}248.4^{\mathrm{c}} \\
\pm 1.52 \\
\end{array}$ & $\begin{array}{l}209.2^{\mathrm{jk}} \\
\pm 2.52\end{array}$ & $\begin{array}{l}221.0^{\mathrm{hi}} \\
\pm 2.45\end{array}$ & $\begin{array}{l}237.2^{\mathrm{de}} \\
\pm 2.63\end{array}$ & $\begin{array}{l}240.6^{\text {cde }} \\
\pm 2.18\end{array}$ & \begin{tabular}{r|}
$211.7^{\mathrm{A}}$ \\
\pm 8.54 \\
\end{tabular} \\
\hline $\begin{array}{c}\text { End of } 4^{\text {th }} \text { week } \\
\pm \text { S. E. }\end{array}$ & $\begin{array}{l}117.4^{\mathrm{q}} \\
\pm 2.16\end{array}$ & $\begin{array}{l}322.9^{\mathrm{b}} \\
\pm 5.58\end{array}$ & $\begin{array}{l}185.8^{\mathrm{mn}} \\
\pm 2.29\end{array}$ & $\begin{array}{l}198.8^{1} \\
\pm 2.44\end{array}$ & $\begin{array}{l}226.4^{\mathrm{gh}} \\
\pm 2.11\end{array}$ & $\begin{array}{c}232.8^{\mathrm{efg}} \\
\pm 2.08\end{array}$ & $\mid \begin{array}{c}214.0^{\mathrm{A}} \\
\pm \\
11.48\end{array}$ \\
\hline $\begin{array}{c}\text { End of } 5^{\text {th }} \text { week } \\
\pm \text { S. E. }\end{array}$ & $\begin{array}{l}120.1^{\mathrm{q}} \\
\pm 2.20\end{array}$ & $\begin{array}{l}325.0^{\mathrm{b}} \\
\pm 4.64\end{array}$ & $\begin{array}{l}177.2^{\text {op }} \\
\pm 2.13\end{array}$ & $\begin{array}{l}189.0^{\mathrm{mn}} \\
\pm 1.76\end{array}$ & $\begin{array}{l}210.8^{\mathrm{jk}} \\
\pm 3.18\end{array}$ & $\begin{array}{l}219.0^{\mathrm{hi}} \\
\pm 3.91\end{array}$ & $\begin{array}{c}206.9^{\mathrm{B}} \\
\pm \\
11.52\end{array}$ \\
\hline $\begin{array}{c}\text { End of } 6^{\text {th }} \text { week } \\
\pm \text { S. E. }\end{array}$ & $\begin{array}{l}121.4^{\mathrm{q}} \\
\pm 3.33\end{array}$ & $\begin{array}{l}349.7^{\mathrm{a}} \\
\pm 2.32\end{array}$ & $\begin{array}{l}172.2^{p} \\
\pm 1.02\end{array}$ & $\begin{array}{l}181.8^{\text {no }} \\
\pm 0.92\end{array}$ & $\begin{array}{l}193.8^{\mathrm{lm}} \\
\pm 2.82\end{array}$ & $\begin{array}{l}197.8^{1} \\
\pm 1.24\end{array}$ & $\begin{array}{c}202.8^{\mathrm{C}} \\
\pm \\
13.09\end{array}$ \\
\hline Mean & $\begin{array}{l}112.0^{\mathrm{F}} \\
\pm 2.03 \\
\end{array}$ & $\begin{array}{l}283.7^{\mathrm{A}} \\
\pm 9.38 \\
\end{array}$ & $\begin{array}{l}193.5^{\mathrm{E}} \\
\pm 3.02 \\
\end{array}$ & $\begin{array}{l}204.5^{\mathrm{D}} \\
\pm 2.99 \\
\end{array}$ & $\begin{array}{l}221.7^{\mathrm{C}} \\
\pm 3.00 \\
\end{array}$ & $\begin{array}{l}228.4^{\mathrm{B}} \\
\pm 3.19 \\
\end{array}$ & \\
\hline
\end{tabular}

S. E. = Standard Error

Values followed by the same letter within the same column were not significantly different $(\mathrm{P}<0.05)$.
F. Test (A) (week) $=18.88^{* *}$
F. Test (AB)
$=106.54^{* *}$
F. Test (B) (Tre.) $=2444.19^{* * *}$

\section{Serum HDL (High Density Lipoprotein) in the two studied mushroom varieties:}

The results given in table (7) revealed that the serum HDL of the experimental animals showed significant differences among all the six studied groups at $(\mathrm{P}<0.05)$ in experimental period.

However, the data showed significant differences between group (1) (control group fed on basal diet) recording $(52.61 \pm 1.11 \mathrm{mg} / \mathrm{dl})$ and all other groups in the two studied mushroom varieties namely: (Agaricus 
bisporus) and (Pleurotus ostrreats).

On the other hand, significant differences between group (2) (untreated group fed on hyperlipidemic diet) recording $(53.07 \pm 0.77 \mathrm{mg} / \mathrm{dl})$ and groups $(3,4,5$ and 6$)$ were recorded.

However, the serum HDL cholesterol in group (3) (treated group fed on hyperlipidemic diet plus 10\% Agaricus bisporus / rat) recorded increased significantly at $(\mathrm{P}<0.05)$ recording $(81.22 \pm 3.08 \mathrm{mg} / \mathrm{dl})$.

But, the serum HDL cholesterol in groups (4, 5 and 6) (treated group fed on hyperlipidemic diet plus $10 \%$ Pleurotus ostreatus, treated group fed on hyperlipidiemic diet plus 5\% Agaricus bisporus and treated group fed on hyperlipidemic diet plus 5\% Pleurotus ostreatus / rats) recorded (76.86 $\pm 2.51 \mathrm{mg} / \mathrm{dl}, 72.60 \pm 2.14 \mathrm{mg} / \mathrm{dl}$ and $66.07 \pm 1.62 \mathrm{mg} / \mathrm{dl}$ ); respectively.

The data given in table (7) revealed that the mean values among all six studied treatments recorded significant increase starting from 58. 52 and reaching 77.75 by the end of the feeding experiment.

The present results given in table (7) were agreed with. Oyetayo (2006) who found high density lipoprotein cholesterol were significantly higher $(\mathrm{P}<0.05)$ when rats fed on mushroom diets. 
Table (7): Effect of the six studied groups on the serum HDL content (mg / dl) of the experimental rats.

\begin{tabular}{|c|c|c|c|c|c|c|c|}
\hline \multirow[t]{2}{*}{$\begin{array}{c}\text { Time of } \\
\text { observation }\end{array}$} & 它 & 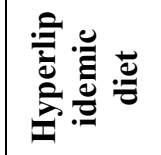 & 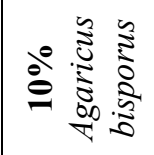 & 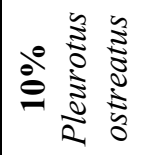 & 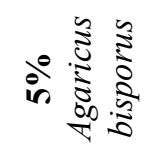 & 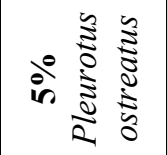 & \multirow[t]{2}{*}{ Mean } \\
\hline & Group 1 & Group 2 & Group 3 & Group 4 & Group 5 & Group 6 & \\
\hline $\begin{array}{c}\text { End of } 1^{\text {st }} \text { week } \\
\pm \text { S. E. }\end{array}$ & $\begin{array}{c}51.12^{\mathrm{qrs}} \\
\pm 1.94\end{array}$ & $\begin{array}{c}52.00^{\mathrm{pqr}} \\
\pm 2.61\end{array}$ & $\begin{array}{c}67.48^{\text {hij }} \\
\pm 5.07\end{array}$ & $\begin{array}{l}63.31^{\mathrm{ijkl}} \\
\pm 2.92\end{array}$ & $\begin{array}{c}59.20^{\mathrm{klmno}} \\
\pm 2.73\end{array}$ & $\begin{array}{c}58.01^{\text {Imnopq }} \\
\pm 2.55\end{array}$ & $\begin{array}{l}58.52^{\mathrm{E}} \\
\pm 1.58\end{array}$ \\
\hline $\begin{array}{c}\text { End of } 2^{\text {nd }} \text { week } \\
\pm \text { S. E. }\end{array}$ & $\begin{array}{c}56.40^{\text {Imnopqr }} \\
\pm 1.69 \\
\end{array}$ & $\begin{array}{c}52.40^{\mathrm{opqr}} \\
\pm 2.52 \\
\end{array}$ & $\begin{array}{c}58.52^{\mathrm{klmnop}} \\
\pm 3.27\end{array}$ & $\begin{array}{c}59.87^{\mathrm{k} / m n} \\
\pm 2.16 \\
\end{array}$ & $\begin{array}{c}61.80^{\mathrm{j} \mathrm{klm}} \\
\pm 1.28 \\
\end{array}$ & $\begin{array}{c}55.40^{\text {mnopqr }} \\
\pm 1.72 \\
\end{array}$ & $\begin{array}{l}57.40^{\mathrm{E}} \\
\pm 1.00 \\
\end{array}$ \\
\hline $\begin{array}{c}\text { End of } 3^{\text {rd }} \text { week } \\
\pm \text { S. E. }\end{array}$ & $\begin{array}{c}59.40^{\mathrm{K} / \mathrm{mno}} \\
\pm 2.56\end{array}$ & $\begin{array}{c}54.80^{\text {mnopqr }} \\
\pm 1.98\end{array}$ & $\begin{array}{l}78.94^{\mathrm{fg}} \\
\pm 2.22\end{array}$ & $\begin{array}{l}73.27^{\text {gh }} \\
\pm 1.25\end{array}$ & $\begin{array}{l}67.60^{\mathrm{hij}} \\
\pm 1.50\end{array}$ & $\begin{array}{l}65.20^{\mathrm{ijk}} \\
\pm 2.48\end{array}$ & $\begin{array}{l}66.54^{\mathrm{D}} \\
\pm 1.68\end{array}$ \\
\hline $\begin{array}{c}\text { End of } 4^{\text {th }} \text { week } \\
\quad \pm \text { S. E. }\end{array}$ & $\begin{array}{l}53.00^{\text {nopqr }} \\
\pm 1.05\end{array}$ & $\begin{array}{c}54.40^{\text {nopqr }} \\
\pm 0.68\end{array}$ & $\begin{array}{l}85.46^{\mathrm{de}} \\
\pm 3.17\end{array}$ & $\begin{array}{l}80.71^{\text {ef }} \\
\pm 1.46\end{array}$ & $\begin{array}{l}76.00^{\mathrm{fg}} \\
\pm 1.76\end{array}$ & $\begin{array}{l}69.00^{\mathrm{hi}} \\
\pm 2.77\end{array}$ & $\begin{array}{l}69.76^{\mathrm{C}} \\
\pm 2.42\end{array}$ \\
\hline $\begin{array}{c}\text { End of } 5^{\text {th }} \text { week } \\
\pm \text { S. E. }\end{array}$ & $\begin{array}{l}45.20^{\mathrm{s}} \\
\pm 2.84\end{array}$ & $\begin{array}{c}55.20^{\text {mnopqr }} \\
\pm 0.80\end{array}$ & $\begin{array}{l}93.22^{\mathrm{bc}} \\
\pm 2.10\end{array}$ & $\begin{array}{l}87.11^{\text {cde }} \\
\pm 1.07\end{array}$ & $\begin{array}{l}81.00^{\mathrm{ef}} \\
\pm 2.07\end{array}$ & $\begin{array}{l}73.00^{\mathrm{gh}} \\
\pm 1.87\end{array}$ & $\begin{array}{l}72.46^{\mathrm{B}} \\
\pm 3.26\end{array}$ \\
\hline $\begin{array}{c}\text { End of } 6^{\text {th }} \text { week } \\
\pm \text { S. E. }\end{array}$ & $\begin{array}{l}50.56^{\mathrm{rs}} \\
\pm 0.58\end{array}$ & $\begin{array}{l}49.60^{\mathrm{rs}} \\
\pm 1.44\end{array}$ & $\begin{array}{l}103.70^{\mathrm{a}} \\
\pm 3.47\end{array}$ & $\begin{array}{l}96.86^{\mathrm{b}} \\
\pm 2.09\end{array}$ & $\begin{array}{l}90.00^{\mathrm{cd}} \\
\pm 2.17\end{array}$ & $\begin{array}{l}75.80^{\mathrm{fg}} \\
\pm 2.13\end{array}$ & $\begin{array}{l}77.75^{\mathrm{A}} \\
\pm 4.04\end{array}$ \\
\hline Mean & $\begin{array}{l}52.61^{\mathrm{E}} \\
\pm 1.11\end{array}$ & $\begin{array}{l}53.07^{\mathrm{E}} \\
\pm 0.77\end{array}$ & $\begin{array}{r}81.22^{\mathrm{A}} \\
\pm 3.08\end{array}$ & $\begin{array}{l}76.86^{\mathrm{D}} \\
\pm 2.51\end{array}$ & $\begin{array}{l}72.60^{\mathrm{C}} \\
\pm 2.14\end{array}$ & $\begin{array}{l}66.07^{\mathrm{D}} \\
\pm 1.62\end{array}$ & \\
\hline
\end{tabular}

S. E. = Standard Error

Values followed by the same letter within the same column were not significantly different $(\mathrm{P}<0.05)$.
F. Test (A) (week) $=84.15^{* *}$
F. Test (B) (Tre.) $=194.31^{* *}$
F. Test (AB)
$=14.67^{* *}$

Serum LDL (Low Density Lipoprotein) in the two studied mushroom varieties:

The results given in table (8) revealed that the serum LDL showed significant differences among all the six studied groups, all feeding weeks at $(\mathrm{P}<0.05)$ in experimental period.

Meanwhile, the data regarding the serum LDL cholesterol were $(182.1 \pm 8.95 \mathrm{mg} / \mathrm{dl}$ ) for group (2) of experimental rats (untreated group fed on hyperlipidemic diet).

On the other hand, the serum LDL cholesterol in groups $(3,4,5$ and 6) decreased significantly at $(\mathrm{P}<0.05)$ recording $(76.8 \pm 4.97 \mathrm{mg} / \mathrm{dl}$, $88.6 \pm 4.57 \mathrm{mg} / \mathrm{dl}, 106.9 \pm 4.36 \mathrm{mg} / \mathrm{dl}$ and $116.2 \pm 3.80 \mathrm{mg} / \mathrm{dl}$ ); respectively for two groups of mushroom varieties. 
The data given in table (8) revealed that the mean values among all six studied treatments recorded significant decrease starting from 103.4 and reaching 88.3 by the end of the feeding experiment.

The present results given in table (8) were agreed with Shahdat et al., (2003) who found Mushroom feeding significantly increased plasma fatty acid unsaturation in both normo- and hypercholesterolaemic rats and the 5\% (Pleurotus ostreatus) supplementation provided health benefits, at least partially, by acting on the atherogenic lipid profile in the hypercholesterolaemic condition.

On the other hand, Barter and Rye (1996) found that, lowering of circulating cholesterol especially the low density lipoprotein (LDL) cholesterol fraction could prevent arrest or even reverse coronary atherosclerosis.

Table (8): Effect of the six studied groups on the serum LDL content ( $\mathrm{mg} / \mathrm{dl})$ of the experimental rats.

\begin{tabular}{|c|c|c|c|c|c|c|c|}
\hline \multirow[t]{2}{*}{$\begin{array}{c}\text { Time of } \\
\text { observation }\end{array}$} & ¿̇ & 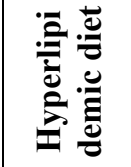 & 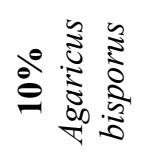 & 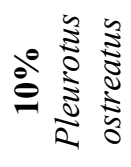 & 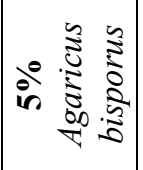 & 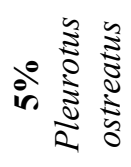 & \multirow[t]{2}{*}{ Mean } \\
\hline & Group 1 & Group 2 & Group 3 & Group 4 & Group 5 & Group 6 & \\
\hline $\begin{array}{c}\text { End of } 1^{\text {st }} \text { week } \\
\pm \text { S. E. }\end{array}$ & $\begin{array}{r}17.9^{q} \\
\pm 3.19 \\
\end{array}$ & $\begin{array}{l}129.5^{\mathrm{ef}} \\
\pm 2.36\end{array}$ & $\begin{array}{l}102.4^{\mathrm{k}} \\
\pm 4.40\end{array}$ & $\begin{array}{l}113.9^{\mathrm{hij}} \\
\pm 1.07\end{array}$ & $\begin{array}{l}126.8^{\mathrm{efg}} \\
\pm 2.30\end{array}$ & $\begin{array}{l}130.2^{\mathrm{def}} \\
\pm 1.88\end{array}$ & $\begin{array}{l}103.4^{\mathrm{B}} \\
\pm 7.41\end{array}$ \\
\hline \begin{tabular}{|c|} 
End of $2^{\text {nd }}$ \\
week \\
\pm S. E. \\
\end{tabular} & $\begin{array}{r}20.4^{\mathrm{q}} \\
\pm 3.82\end{array}$ & $\begin{array}{l}135.1^{\text {cde }} \\
\pm 2.22\end{array}$ & $\begin{array}{l}110.1^{\mathrm{ijk}} \\
\pm 2.70\end{array}$ & $\begin{array}{l}115.0^{\mathrm{hi}} \\
\pm 2.09\end{array}$ & $\begin{array}{l}126.9^{\mathrm{efg}} \\
\pm 3.50\end{array}$ & $\begin{array}{l}139.8^{\mathrm{cd}} \\
\pm 3.00\end{array}$ & $\begin{array}{l}107.9^{\mathrm{A}} \\
\pm 7.60\end{array}$ \\
\hline $\begin{array}{c}\text { End of } 3^{\text {rd }} \text { week } \\
\pm \text { S. E. }\end{array}$ & $\begin{array}{r}25.6^{\mathrm{q}} \\
\pm 4.43 \\
\end{array}$ & $\begin{array}{l}143.8^{\mathrm{c}} \\
\pm 2.38 \\
\end{array}$ & $\begin{array}{r}89.6^{1} \\
\pm 3.71 \\
\end{array}$ & $\begin{array}{l}104.2^{\mathrm{jk}} \\
\pm 3.09 \\
\end{array}$ & $\begin{array}{l}123.2^{\text {fgh }} \\
\pm 3.35 \\
\end{array}$ & $\begin{array}{l}126.8^{\mathrm{efg}} \\
\pm 3.05 \\
\end{array}$ & $\begin{array}{l}102.2^{\mathrm{B}} \\
\pm 7.23 \\
\end{array}$ \\
\hline $\begin{array}{c}\text { End of } 4^{\text {th }} \text { week } \\
\pm \text { S. E. }\end{array}$ & $\begin{array}{l}35.6^{\mathrm{p}} \\
\pm 2.80 \\
\end{array}$ & $\begin{array}{l}216.7^{b} \\
\pm 5.57 \\
\end{array}$ & $\begin{array}{r}65.2^{\mathrm{n}} \\
\pm 4.62 \\
\end{array}$ & $\begin{array}{r}79.6^{\mathrm{m}} \\
\pm 3.41 \\
\end{array}$ & $\begin{array}{l}108.6^{\mathrm{ijk}} \\
\pm 2.22\end{array}$ & $\begin{array}{l}116.6^{\mathrm{ghi}} \\
\pm 4.27\end{array}$ & $\begin{array}{r}103.7^{\mathrm{B}} \\
\pm 10.73 \\
\end{array}$ \\
\hline $\begin{array}{c}\text { End of } 5^{\text {th }} \text { week } \\
\pm \text { S. E. }\end{array}$ & $\begin{array}{l}45.3^{\mathrm{op}} \\
\pm 4.68 \\
\end{array}$ & $\begin{array}{l}216.3^{b} \\
\pm 4.56\end{array}$ & $\begin{array}{r}52.9^{\circ} \\
\pm 3.79 \\
\end{array}$ & $\begin{array}{r}66.4^{\mathrm{n}} \\
\pm \quad 3.10 \\
\end{array}$ & $\begin{array}{r}89.8^{1} \\
\pm 4.06 \\
\end{array}$ & $\begin{array}{l}102.2^{\mathrm{k}} \\
\pm 4.03 \\
\end{array}$ & $\begin{array}{r}95.5^{\mathrm{C}} \\
\pm 10.79 \\
\end{array}$ \\
\hline $\begin{array}{c}\text { End of } 6^{\text {th }} \text { week } \\
\pm \text { S. E. }\end{array}$ & $\begin{array}{r}38.7^{\mathrm{p}} \\
\pm 3.88 \\
\end{array}$ & $\begin{array}{l}250.9^{\mathrm{a}} \\
\pm 5.19 \\
\end{array}$ & $\begin{array}{r}40.5^{\mathrm{p}} \\
\pm 3.02 \\
\end{array}$ & $\begin{array}{r}52.4^{\circ} \\
\pm 2.47 \\
\end{array}$ & $\begin{array}{r}66.2^{\mathrm{n}} \\
\pm 5.00 \\
\end{array}$ & $\begin{array}{l}81.3^{\operatorname{lm}} \\
\pm 1.98 \\
\end{array}$ & $\begin{array}{r}88.3^{\mathrm{D}} \\
\pm 13.85 \\
\end{array}$ \\
\hline Mean & $\begin{array}{c}30.6^{\mathrm{F}} \\
\pm 2.34\end{array}$ & $\begin{array}{l}182.1^{\mathrm{A}} \\
\pm 8.95\end{array}$ & $\begin{array}{r}76.8^{\mathrm{E}} \\
\pm 4.97\end{array}$ & $\begin{array}{c}88.6^{\mathrm{D}} \\
\pm 4.57\end{array}$ & $\begin{array}{l}106.9^{\mathrm{C}} \\
\pm 4.36\end{array}$ & $\begin{array}{l}116.2^{\mathrm{B}} \\
\pm 3.80\end{array}$ & \\
\hline
\end{tabular}

S. E. $=$ Standard Error

Values followed by the same letter within the same column were not significantly different $(\mathrm{P}<0.05)$. 

F. Test (A) (week) $=26.93^{* *}$
F. Test (B) (Tre.) $=1356.96^{* *}$
F. Test $(\mathrm{AB})=91.54^{* *}$

Serum VLDL cholesterol in the two studied mushroom varieties:

The results given in table (9) revealed that the serum VLDL cholesterol showed significant differences among all studied groups at $(\mathrm{P}<$ 0.05) in experimental period.

However, the data regarding the blood serum VLDL-cholesterol were $(48.59 \pm 0.78 \mathrm{mg} / \mathrm{dl})$ for group (2) of experimental rats (untreated group fed on hyperlipidemic diet).

Likewise, the serum VLDL-cholesterol decreased significantly at ( $\mathrm{P}$ $<0.05)$ for groups $(3,4,5$ and 6$)$ of experimental rats to recording $(35.43 \pm 0.92 \mathrm{mg} / \mathrm{dl}$ ) for group (3) of experimental rats (treated group fed on hyperlipidemic diet plus 10\% Agaricus bisporus / rat), $(38.76 \pm 0.74 \mathrm{mg} / \mathrm{dl})$ for group (4) of rat (treated group fed on hyperlimpidemic diet plus $10 \%$ Pleurotus ostrreats / rat), $(42.22 \pm 0.61 \mathrm{mg} / \mathrm{dl})$ for group (5) of rat (treated group fed on hyperlipidemic diet plus 5\% Agaricus bisporus / rat) and $(45.46 \pm 0.60 \mathrm{mg} / \mathrm{dl})$ for group (6) of rat (treated group fed on hyperlipidemic diet plus 5\% Pleurotus ostrreats / rat); respectively.

The data given in table (9) revealed that the mean values among all six studied treatments recorded significant decrease starting from 38.60 and reaching 36.64 by the end of the feeding experiment.

The present results given in table (9) were agreed with Pavel $\boldsymbol{e t}$ al., (1997) who found that, dose 5\% of Oyster mushroom reduced cholesterol content very low density lipoproteins and VLDL. 
Table (9): Effect of the six studied groups on the serum VLDL content $(\mathrm{mg} / \mathrm{dl})$ of the experimental rats.

\begin{tabular}{|c|c|c|c|c|c|c|c|}
\hline \multirow[t]{2}{*}{$\begin{array}{c}\text { Time of } \\
\text { observation }\end{array}$} & 葛 & 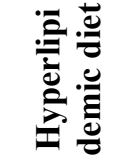 & 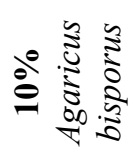 & 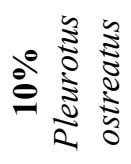 & 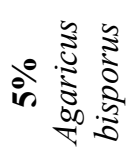 & 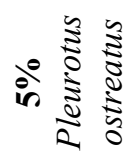 & \multirow[t]{2}{*}{ Mean } \\
\hline & Group 1 & Group 2 & Group 3 & Group 4 & Group 5 & Group 6 & \\
\hline $\begin{array}{c}\text { End of } 1^{\text {st }} \text { week } \\
\pm S . \text { E. }\end{array}$ & $\begin{array}{l}26.42^{\mathrm{q}} \\
\pm 0.80 \\
\end{array}$ & $\begin{array}{l}41.72^{\text {ghi }} \\
\pm 0.16 \\
\end{array}$ & $\begin{array}{l}38.08^{\mathrm{jk}} \\
\pm 0.68 \\
\end{array}$ & $\begin{array}{l}39.82^{\mathrm{ij}} \\
\pm 0.52 \\
\end{array}$ & $\begin{array}{l}41.57^{\text {ghi }} \\
\pm 0.53\end{array}$ & $\begin{array}{l}44.00^{\mathrm{ef}} \\
\pm 0.44\end{array}$ & $\begin{array}{l}38.60^{\mathrm{D}} \\
\pm 1.09\end{array}$ \\
\hline $\begin{array}{l}\text { End of } 2^{\text {nd }} \text { week } \\
\pm \text { S. E. }\end{array}$ & $\begin{array}{l}27.44^{\mathrm{pq}} \\
\pm 0.78\end{array}$ & $\begin{array}{l}45.47^{\mathrm{de}} \\
\pm 0.26\end{array}$ & $\begin{array}{l}40.00^{1 \mathrm{j}} \\
\pm 0.58 \\
\end{array}$ & $\begin{array}{l}42.58^{\mathrm{fgh}} \\
\pm 0.57\end{array}$ & $\begin{array}{l}45.92^{\mathrm{d}} \\
\pm 0.23\end{array}$ & $\begin{array}{l}48.58^{\mathrm{bc}} \\
\pm 0.64\end{array}$ & $\begin{array}{l}41.67^{\mathrm{B}} \\
\pm 1.30 \\
\end{array}$ \\
\hline $\begin{array}{c}\text { End of } 3^{\text {rd }} \text { week } \\
\pm \text { S. E. }\end{array}$ & $\begin{array}{c}28.24^{\mathrm{opq}} \\
\pm 1.22\end{array}$ & $\begin{array}{l}49.86^{\mathrm{b}} \\
\pm 0.61\end{array}$ & $\begin{array}{l}40.64^{\mathrm{hi}} \\
\pm 0.56\end{array}$ & $\begin{array}{l}43.54^{\mathrm{fg}} \\
\pm 0.35\end{array}$ & $\begin{array}{l}46.44^{\mathrm{d}} \\
\pm 0.35\end{array}$ & $\begin{array}{l}48.60^{\mathrm{bc}} \\
\pm 0.99\end{array}$ & $\begin{array}{l}42.89^{\mathrm{A}} \\
\pm 1.37\end{array}$ \\
\hline $\begin{array}{c}\text { End of } 4^{\text {th }} \text { week } \\
\pm \text { S. E. }\end{array}$ & $\begin{array}{l}28.78^{\mathrm{op}} \\
\pm 0.97 \\
\end{array}$ & $\begin{array}{l}51.78^{\mathrm{a}} \\
\pm 0.58 \\
\end{array}$ & $\begin{array}{l}35.16^{1} \\
\pm 1.01 \\
\end{array}$ & $\begin{array}{l}38.48^{\mathrm{jk}} \\
\pm 0.73 \\
\end{array}$ & $\begin{array}{l}41.80^{\text {ghi }} \\
\pm 0.54\end{array}$ & $\begin{array}{l}47.16^{\mathrm{cd}} \\
\pm 0.34\end{array}$ & $\begin{array}{l}40.53^{\mathrm{C}} \\
\pm 1.43 \\
\end{array}$ \\
\hline $\begin{array}{c}\text { End of } 5^{\text {th }} \text { week } \\
\pm \text { S. E. }\end{array}$ & $\begin{array}{l}29.64^{\text {no }} \\
\pm 1.06\end{array}$ & $\begin{array}{l}53.50^{\mathrm{a}} \\
\pm 0.28\end{array}$ & $\begin{array}{l}31.08^{\mathrm{mn}} \\
\pm 0.92\end{array}$ & $\begin{array}{l}35.54^{1} \\
\pm 0.71\end{array}$ & $\begin{array}{l}40.00^{\mathrm{ij}} \\
\pm 0.53\end{array}$ & $\begin{array}{l}43.76^{\mathrm{ef}} \\
\pm 0.53\end{array}$ & $\begin{array}{l}38.92^{\mathrm{D}} \\
\pm 1.53\end{array}$ \\
\hline $\begin{array}{c}\text { End of } 6^{\text {th }} \text { week } \\
\pm \text { S. E. }\end{array}$ & $\begin{array}{l}32.16^{\mathrm{m}} \\
\pm 0.80\end{array}$ & $\begin{array}{l}49.18^{\mathrm{b}} \\
\pm 1.47 \\
\end{array}$ & $\begin{array}{l}27.64^{\mathrm{pq}} \\
\pm 0.59 \\
\end{array}$ & $\begin{array}{l}32.60^{\mathrm{m}} \\
\pm 0.53\end{array}$ & $\begin{array}{l}37.56^{\mathrm{k}} \\
\pm 0.75\end{array}$ & $\begin{array}{l}40.68^{\mathrm{hi}} \\
\pm 1.01\end{array}$ & $\begin{array}{l}36.64^{\mathrm{E}} \\
\pm 1.34 \\
\end{array}$ \\
\hline Mean & $\begin{array}{c}28.781^{\mathrm{F}} \\
\pm 0.49 \\
\end{array}$ & $\begin{array}{l}48.59^{\mathrm{A}} \\
\pm 0.78 \\
\end{array}$ & $\begin{array}{l}35.43^{\mathrm{E}} \\
\pm 0.92 \\
\end{array}$ & $\begin{array}{l}38.76^{\mathrm{D}} \\
\pm 0.74 \\
\end{array}$ & $\begin{array}{l}42.22^{\mathrm{C}} \\
\pm 0.61 \\
\end{array}$ & $\begin{array}{l}45.46^{\mathrm{B}} \\
\pm 0.60 \\
\end{array}$ & \\
\hline
\end{tabular}

S. E. = Standard Error

Values followed by the same letter within the same column were not significantly different $(\mathrm{P}<0.05)$.
F. Test (A) (week) $=76.89^{* * *}$
F. Test (B) (Tre.) $=797.15^{* *}$
F. Test (AB)
$=28.84^{* * *}$ 


\section{Serum glucose in the two studied mushroom varieties:}

The results given in table (10) revealed that the serum glucose showed significant differences among all the six studied groups, all feeding weeks as well as interaction studied groups and feeding weeks at $(\mathrm{P}<0.05)$ in experimental period.

However, the data regarding the serum glucose were (130.8 \pm 4.17 $\mathrm{mg} / \mathrm{dl}$ ) for group (2) of experimental rats (untreated group fed on hyperlipidemic diet).

Likewise, the serum glucose decreased significantly at $(\mathrm{P}<0.05)$ for groups $(3,4,5$ and 6$)$ of experimental rats to recording $(106.8 \pm 1.98 \mathrm{mg} /$ dl) for group (3) of experimental rats (treated group fed on hyperlipidemic diet plus 10\% Agaricus bisporus / rat), (113.3 $\pm 2.08 \mathrm{mg} / \mathrm{dl})$ for group (4) of rat (treated group fed on hyperlimpidemic diet plus $10 \%$ Pleurotus ostrreats / rat), (119.8 $\pm 2.37 \mathrm{mg} / \mathrm{dl})$ for group (5) of rat (treated group fed on hyperlipidemic diet plus 5\% Agaricus bisporus / rat) and (122.4 $\pm 2.47 \mathrm{mg} /$ dl) for group (6) of rat (treated group fed on hyperlipidemic diet plus 5\% Pleurotus ostrreats / rat); respectively.

The data given in table (10) revealed that the mean values among all six studied treatments recorded significant increase starting from 91.8 and reaching 120.7 by the end of the feeding experiment.

Table (10): Effect of the six studied groups on the serum glucose content (mg / dl) of the experimental rats.

\begin{tabular}{|c|c|c|c|c|c|c|c|}
\hline \multirow[t]{2}{*}{$\begin{array}{c}\text { Time of } \\
\text { observation }\end{array}$} & 葛 & 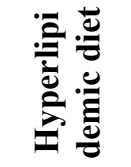 & 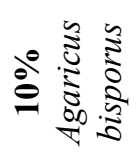 & 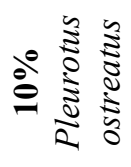 & 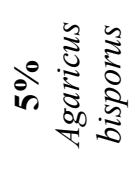 & 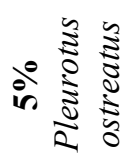 & \multirow[t]{2}{*}{ Mean } \\
\hline & Group 1 & Group 2 & Group 3 & Group 4 & Group 5 & Group 6 & \\
\hline $\begin{array}{c}\text { End of } 1^{\text {st }} \text { week } \\
\pm \text { S. E. }\end{array}$ & $\begin{array}{l}90.8^{\text {op }} \\
\pm 2.19\end{array}$ & $\begin{array}{l}90.8^{\text {op }} \\
\pm 1.77\end{array}$ & $\begin{array}{l}87.6^{\mathrm{p}} \\
\pm 1.24\end{array}$ & $\begin{array}{l}91.4^{\text {nop }} \\
\pm 1.40\end{array}$ & $\begin{array}{l}95.3^{\mathrm{mno}} \\
\pm 1.79\end{array}$ & $\begin{array}{l}95.1^{\mathrm{mno}} \\
\pm 2.62\end{array}$ & $\begin{array}{l}91.8^{\mathrm{C}} \\
\pm 0.86\end{array}$ \\
\hline $\begin{array}{c}\text { End of } 2^{\text {nd }} \text { week } \\
\pm \text { S. E. }\end{array}$ & $\begin{array}{l}98.1^{\operatorname{lm}} \\
\pm 5.28\end{array}$ & $\begin{array}{l}119.4^{\mathrm{fg}} \\
\pm 0.92\end{array}$ & $\begin{array}{l}111.1^{1 \mathrm{j}} \\
\pm 2.81\end{array}$ & $\begin{array}{l}113.6^{\text {ghij }} \\
\pm 2.98\end{array}$ & $\begin{array}{l}116.1^{\text {fghi }} \\
\pm 3.37\end{array}$ & $\begin{array}{l}122.4^{\mathrm{ef}} \\
\pm 2.34\end{array}$ & $\begin{array}{l}113.5^{\mathrm{B}} \\
\pm 1.88\end{array}$ \\
\hline $\begin{array}{c}\text { End of } 3^{\text {rd }} \text { week } \\
\pm \text { S. E. }\end{array}$ & $\begin{array}{l}97.2^{\operatorname{lmn}} \\
\pm 0.64\end{array}$ & $\begin{array}{l}129.1^{\mathrm{d}} \\
\pm 3.17\end{array}$ & $\begin{array}{l}120.6^{\mathrm{ef}} \\
\pm 1.17\end{array}$ & $\begin{array}{l}125.6^{\mathrm{de}} \\
\pm 1.74\end{array}$ & $\begin{array}{l}130.6^{\mathrm{d}} \\
\pm 2.88\end{array}$ & $\begin{array}{l}131.6^{\mathrm{d}} \\
\pm 3.07\end{array}$ & $\begin{array}{l}122.5^{\mathrm{A}} \\
\pm 2.37\end{array}$ \\
\hline $\begin{array}{c}\text { End of } 4^{\text {th }} \text { week } \\
\pm \text { S. E. }\end{array}$ & $\begin{array}{r}101.7^{1} \\
\pm 2.70 \\
\end{array}$ & $\begin{array}{l}139.0^{\mathrm{c}} \\
\pm 2.67 \\
\end{array}$ & $\begin{array}{l}108.6^{\mathrm{jk}} \\
\pm 2.58 \\
\end{array}$ & $\begin{array}{l}118.7^{\text {fgh }} \\
\pm 1.06 \\
\end{array}$ & $\begin{array}{l}128.7^{\mathrm{d}} \\
\pm 1.19 \\
\end{array}$ & $\begin{array}{l}130.0^{\mathrm{d}} \\
\pm 1.46 \\
\end{array}$ & $\begin{array}{l}121.1^{\mathrm{A}} \\
\pm 2.51 \\
\end{array}$ \\
\hline
\end{tabular}




\begin{tabular}{|c|c|c|c|c|c|c|c|}
\hline $\begin{array}{c}\text { End of } 5^{\text {th }} \text { week } \\
\pm \text { S. E. }\end{array}$ & $\begin{array}{l}97.9^{\operatorname{lm}} \\
\pm 1.84 \\
\end{array}$ & $\begin{array}{l}148.3^{\mathrm{b}} \\
\pm 2.58 \\
\end{array}$ & $\begin{array}{r}109.7^{j} \\
\pm 1.29\end{array}$ & $\begin{array}{l}117.7^{\text {fgh }} \\
\pm 0.94\end{array}$ & $\begin{array}{l}125.7^{\mathrm{de}} \\
\pm 1.72\end{array}$ & $\begin{array}{l}129.0^{\mathrm{d}} \\
\pm 1.40\end{array}$ & $\begin{array}{l}121.4^{\mathrm{A}} \\
\pm 3.01\end{array}$ \\
\hline $\begin{array}{c}\text { End of } 6^{\text {th }} \text { week } \\
\pm \text { S. E. }\end{array}$ & $\begin{array}{l}101.4^{1} \\
\pm 2.49\end{array}$ & $\begin{array}{l}158.3^{\mathrm{a}} \\
\pm 3.70\end{array}$ & $\begin{array}{l}103.1^{\mathrm{kT}} \\
\pm 1.21\end{array}$ & $\begin{array}{l}112.8^{\text {hij }} \\
\pm 1.40\end{array}$ & $\begin{array}{l}122.4^{\mathrm{ef}} \\
\pm 2.01\end{array}$ & $\begin{array}{l}126.2^{\mathrm{de}} \\
\pm 1.46\end{array}$ & $\begin{array}{l}120.7^{\mathrm{A}} \\
\pm 3.64\end{array}$ \\
\hline Mean & $\begin{array}{l}97.9^{\mathrm{F}} \\
\pm 1.26\end{array}$ & $\begin{array}{l}130.8^{\mathrm{A}} \\
\pm 4.17\end{array}$ & $\begin{array}{l}106.8^{\mathrm{E}} \\
\pm 1.98\end{array}$ & $\begin{array}{l}113.3^{\mathrm{D}} \\
\pm 2.08\end{array}$ & $\begin{array}{l}119.8^{\mathrm{C}} \\
\pm 2.37\end{array}$ & $\begin{array}{l}122.4^{\mathrm{B}} \\
\pm 2.47\end{array}$ & \\
\hline
\end{tabular}

S. E. $=$ Standard Error

Values followed by the same letter within the same column were not significantly different $(\mathrm{P}<0.05)$.
F. Test (A) (week) $=214.87^{* * *}$
F. Test $(\mathrm{AB}) \quad=18.19^{* * *}$
F. Test (B) (Tre.) $=210.79^{* *}$

In conclusion, on the basis of above mentioned data, there were significant differences between untreated group and all other (5) studied groups of the experimental rats $(\mathrm{P}<0.05)$ in the serum triglycerides, total cholesterol, HDL cholesterol, LDL cholesterol, VLDL cholesterol and serum glucose levels, while group (3) (treated group fed on hyperlipidemic diet plus 10\% Agaricus bisporus) recorded the lowest mean.

\section{References}

Abd-El-Maksoud, A.M.; Noor E.F. and Abd-El-Galil, A.M. (1996): Study of protective and curative effect of Nigella sativa on serum lipid pattern of rats fed hyperlipidemic diet, Egyptian J. Nutrition, 11(1): 65-85.

Allian, C.C., Poon, L.S., Chan, C.S.G. and Richmond, W. (1974): Enzymatic colourimetric method of the determination of plasma total cholesterol, Clin. Chem. $20: 470$.

Anon. (1977): First Report of The American Institute of Nutrition J. Nutrition, (1977): 107: No. 7, 1340-1348.

Anon. (1980): Second Report of The American Institute of Nutrition J. Nutrition, (1980): 110: No. 8, 1726.

Anon. (2003a): Very high fiber diet lowers blood glucose in diabetics, Medical college of Wisconsin, U.S.A.

Barter, P.J. and Rye, K.A. (1996): High density lipoproteins and coronary heart disease atherosclerosis 121: 1-12.

Bobek, P., Kuniak, L. and Ozdin, L. (1993): The mushroom Pleurotus ostreatus reduces secretion and accelerates the fractional turnover rate of verylow-density lipoproteins in rat. Ann Nutr Metab, 37: 142.

Byrne, K.B. (1991): Understanding and Managing cholesterol, A Guide for Wellness Professionals, Human Kimetics Books Champaign, Illinois.

Cheung, S.T. (1999): World production of cultivated edible and medicinal mushrooms in 1997 with emphasis on lentinus edodes (berk). Sing in China. Journal of Medicinal Mushrooms, I: 291-300. 
Duncan, B.D. (1955): Multiple range and multiple F test, Biometrics, 11: 1-42.

El-Gengaihi, S.E., Sale, A., Bashandi, S.W.A., Ibrahim, S.A. and Abd elHamid, S.R. (2004): Hypolipidemic effects of some vegetable oils in rats Food Agriculture and Environment 2 (2): 88-93.

El-Sayed, H.H.M. (2001): Biological studies on effect of Portulaca oleracea, L. on lowering lipids and blood sugar in experimental animals, $\mathrm{Ph}$. D. Thesis, Faculty of Home Economics, Minufiya University, Minufuya.

Friedewald, W.T., Levy, R. I. and Fredrickson, D.S. (1972): Determination of high density lipoprotein cholesterol by selective precipitation, Clin. Chem. 18: 499 - 502.

Fukushima, M., Nakano, Y., Morii, Y., Ohashi, T., Fujiwara, Y. and Sonoyama, K. (2000): Hepatic LDL receptor mRNA in rats is increased by dietary mushroom (Agraicus bisporous) fiber and sugar beet fiber. J. Nutr. 130: 2151-6.

Grundy, S.M. (1986): Cholesterol and coronary heart disease. Journal of the American Medical Association, 256, 2849-2858.

Hashimoto, M., Hossain, M.S., Shimada, T., Yamasaki, H., Fujii, Y. and Shido, O. (2001): Effects of docosahexaenoic acid on annular lipid fluidity of the rat bile canalicular plasma membrane. J. Lipid Res. 42: $1160-8$.

Hashimoto, M., Shinozuka, K. and Tanabe, Y. (1999): Hypotension induced by exercise is associated with enhanced release of adenyl purines from aged rat artery. Am. J. Physiol. 276: H970-5.

Hussain, F.R., Alwasif, K.H. and Madani, G.M. (2006): Production and Conservation Mushroom, Food Technology Research Institute, Agricultural Research Center. p. 12, 20, The Ministry of Agriculture General Directorate of Agricultural Culture for Publication.

Ilwy, Y.M.E. (2003): The effect of some kinds of sea food (fish) on blood lipid profile in rats. Ph. D. Thesis, Faculty of Specific Education, Ain Shams University.

Kurusawa, S., Sugahara, T. and Hovashi, J. (1982): Studies on dietary fiber of mushroom and edible wild plants. Nutr Rep. Intl. 26: $167-173$.

Mahley, R.W., Weisgraber, K.H., Bergot, T.P. and Innerarity, T.L. (1978): Effects of cholesterol feeding on human and animal high density lipoproteins. In A.M. Gotto, N.E. Miller, and M.F. Oliver (Eds.), High density lipoproteins and atherosclerosis (pp. 149-176). Amsterdam: Elsevier-North Holland.

Manzi, P., Aguzi, P. and Pizzoferrato, L. (2001): Nutritional value of mushroom widely consumed in Italy. Food Chemistry 73: 321-325.

Manzi, P., Gambelli, L., Marconi, S., Vivanti, V. and Pizzoferatto, L. (1999): Nutrients in edible mushroom: An inter species comparative study. Food Chemistry, 65: 477-482. 


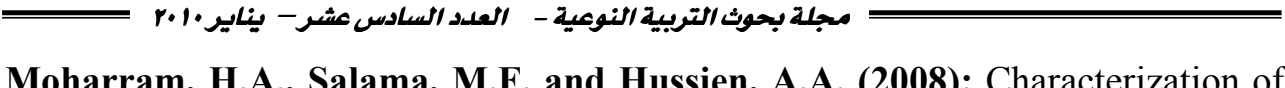
Oyster Mushroom Mycelia as a Food Supplement, Food Technology Department. National Research Centre, Dokki, Cairo, Egypt, Australian Journal of Basic and Applied Sciences, 2(3): 632-642.

Oyetayo, F.L. (2006): Responses of plasma lipids to edible mushroom diets in albino rats. Department of biochemistry, University of Ado-Ekiti, Nigeria. African Journal of Biotechnology Vol. 5 (13), pp. 1263-1266.

Pavel, B., Lubomir, O., and Stefan,G. (1997): Dose - and Time -Dependent Hypocholesterolemic Effect of Oyster Mushroom (Pleurotus ostreatus) in Rats, Research Institute of Nutrition and the Faculty of Medicine, University of J. A. Komensky, Bratislava, Slovak Republic.

Russell, D. F. (1983): MSTAT Director crop and Soil sciences department, Michigan State University, version 2.10.

Schaeffiner, E.S., Kurth, T., Curhan, G.C., Glynn, R.J., Rexrode, K.M.; Baigent, C.; During, J.E. and Gaziano, J.M. (2003): Cholesterol and the risk of renal dysfunction in apparently healthy men, Journal of the American Society of Naphrology, August, 14(8): 2084-2091.

Shahdat, H., Michio, H., Emran, K.C., Nuhu, A., Shahjalal, H., Moynul, H., Shahabuddin, K.C. and Ishtiaq, M. (2003): dietary mushroom (pleurotus ostreatus) ameliorates atherogenic lipid in hypercholesterol aemic rats, Department of Physiology, Shimane Medical University, Shimane, Japan, Departments of Biochemistry and Molecular Biology, Botany and Pharmacy, Jahangirnagar University, Department of Biochemistry and Molecular Biology, University of Dhaka, International Center for Diarrheal Diseases and Research and Center for Scientific and Industrial Research, Dhaka, Bangladesh, Clinical and Experimental Pharmacology and Physiology, 30, 470475.

Stamlo, J., Welthwoth, D. and Neaton, J.D. (1986): Is there a relationship between serum cholesterol and risk of premature death from coronary heart disease and grade? J Am Med Assoc, 253: 2823.

Trinder, P. (1969): Enzymatic determination of glucose in blood serum, Ann. Clin. Biochemist. $6: 24$.

Wahlefeld, A.W. (1974): In methods of Enzymatic Analysis, Vol. 5, HU Bergmeyer, Ed. Academic Press, New York, pp. 1831-1835.

Warnick, G.R., Benderson, V. and Albers, N. (1983): Selected Methods Clin. Chem. $10:$ 91-99. 


\section{تأثير تناول صنفين هن عيش الغراب على هستوى البليسريدات الثلاثية والكوليستزول والجلوكوز في فئران التجارب \\ أ.د. محمد كمال السيد يوسف" أ.د. فاروق محمد التلاوي"

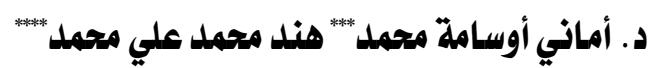

$$
\begin{aligned}
& \text { • قسهم علوم وتكنولوجيا الأغذية ـ كلية الزراعة . جامعة أسيوط }
\end{aligned}
$$

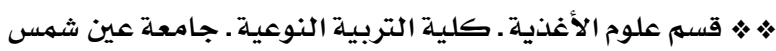

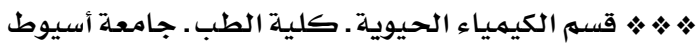

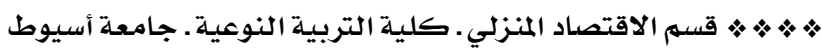

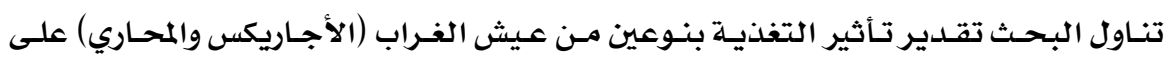

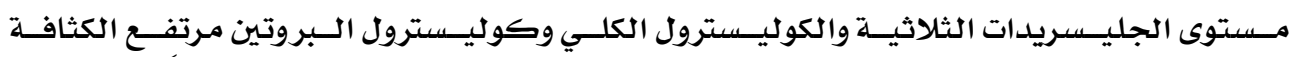

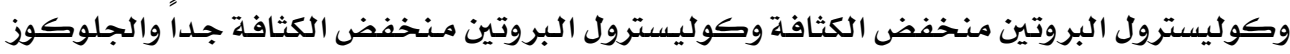

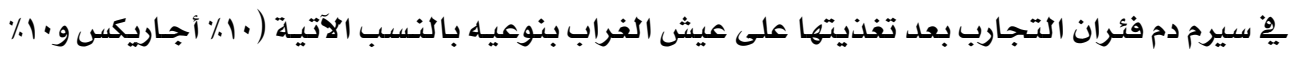

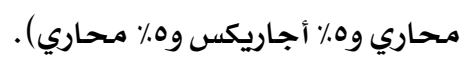

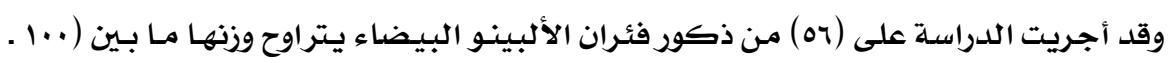

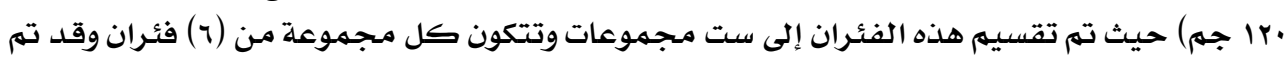

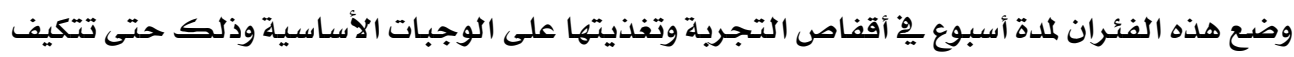

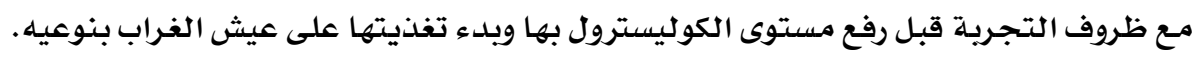

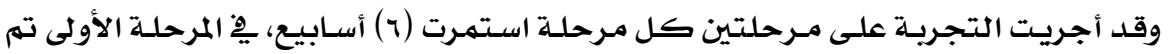

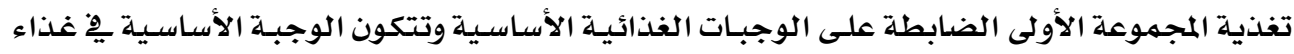

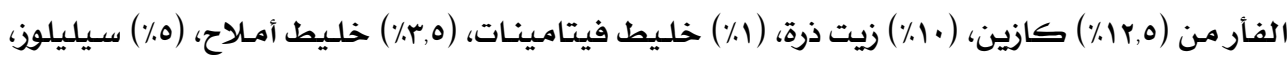

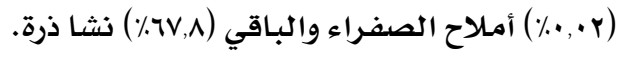

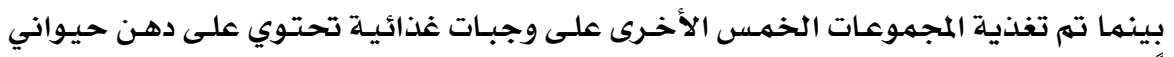

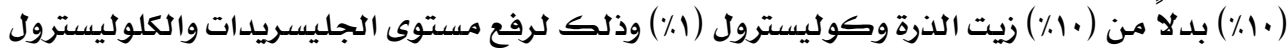
بها يُّ سيرم دم فئران التجارب.

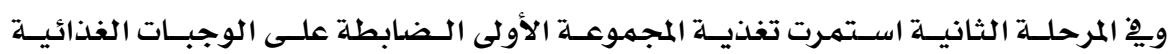

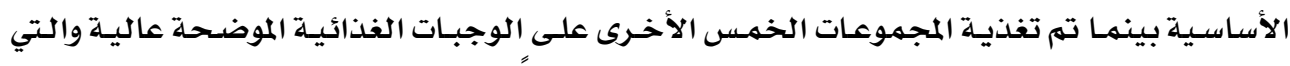

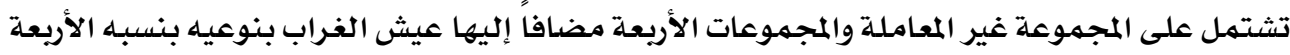
المدروسة. 


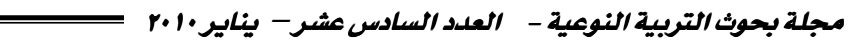

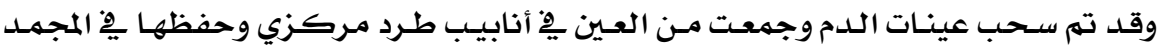

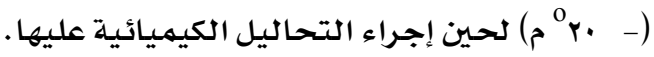

ولقد أوضحت النتائج أنه توجد فروق ذات دلالة إحصائية (0., • ) بـين المجموعة غير المعاملـة

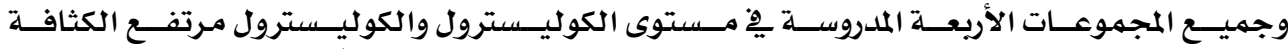

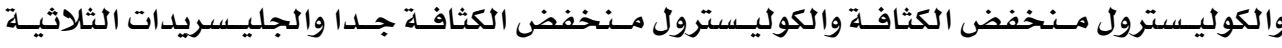

والجلوكوز.

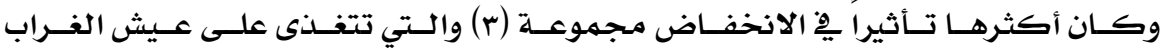

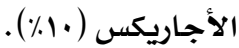

الكلمات المفتاحية:

عيث غراب أجاريكس ـ عيث غراب محاري . جليسريدات ثلاثية ـ زيادة مستوى الليبيدات يِ الدم. 